\title{
Investigating support for Scholarship of Teaching and Learning; We need SoTL educational leaders
}

\author{
Andrea S. Webb* and Anne M. Tierney
}

*Corresponding Author:

Andrea Webb, PhD

Instructor 1, Department of Curriculum \& Pedagogy

Faculty of Education,

The University of British Columbia,

2125 Main Mall,

Vancouver, BC, Canada, V6T 1Z1.

E-mail: andrea.webb@ubc.ca

ORCiDs: 0000-0003-3963-5057

Anne M. Tierney, PhD

Lecturer, Academic Practice

Department of Learning \& Teaching Enhancement,

Edinburgh Napier University

Sighthill Campus, Sighthill Court

Edinburgh, Scotland, U.K., EH11 4BN

E-mail: A.Tierney@napier.ac.uk

ORCiDs: 0000-0001-9032-3361

Andrea S. Webb, PhD: Andrea is an Instructor in Social Studies Education in the Faculty of Education at The University of British Columbia. Website: http://edcp.educ.ubc.ca/faculty-staff/andrea-webb/

Anne M. Tierney, PhD: Anne is a Lecturer and Theme Lead for Research, Scholarship, and Supervision in the Postgraduate Certificate in Learning, Teaching, and Assessment Practice at Edinburgh Napier University. Website: https://www.napier.ac.uk/people/anne-tierney

Word count - 4283 


\begin{abstract}
In this paper, we focus on the experience of faculty learning to do the Scholarship of Teaching and Learning (SoTL). Our two studies uncovered similar threshold concepts in SoTL in two contrasting contexts; one study done in the United Kingdom with teaching-focused academics while the other study, done in North America, focussed on educational leaders at a researchintensive university. Both studies revealed similar ontological and epistemological transformations of learning and doing SoTL. Underpinning the results of these studies is the reality that educational leaders are situated within a complex cultural network of personal, professional, and financial tensions. There are two levels of institutional culture: university level and departmental level. But, institutional policies are only useful if also supported locally. This paper is of interest to those developing their expertise in supporting SoTL, as well as faculty on a teaching and scholarship career route.
\end{abstract}

Keywords: Scholarship of Teaching and Learning; Threshold concepts; Academic Development; Institutional Culture; Higher Education 


\section{Introduction}

This paper is based on a scholarly collaboration between two Scholarship of Teaching and Learning (SoTL) educators at universities in the United Kingdom and Canada. Both of the studies explore threshold concepts (Meyer \& Land, 2003, 2005) in SoTL (Tierney, 2016; Webb, 2015) with educational leaders and teaching-focused academics. The aim of the paper is to compare the results of two empirical studies, situated in our respective contexts, in order to support educational leaders in SoTL. The studies, whilst carried out separately, were pursued to investigate similar aims; namely to explore the existence of and identify the nature of threshold concepts within SoTL. Additionally, the philosophically similar methodologies and methods of data collection serve to align both the studies and the findings. The studies are significant as being the first studies which take an empirical approach to this topic, lending weight to the need for robust and continuing support for faculty who pursue and develop their professional interest in SoTL.

\section{Background}

The landscape of teaching and learning at higher education institutions is complex and constantly changing. Current strategic initiatives require a framework for faculty members to engage with scholarship in teaching and learning to support institutional programme changes and high quality educational experiences for students.

Scholarship of Teaching and Learning. SoTL, a growing movement in higher education, is a distinctive form of research with a broad scope of many interdisciplinary approaches (Hubball \& Clarke, 2010). SoTL sees places of teaching and learning as sites "for inquiry, asking and answering questions about ... learning in ways that can improve ... and also advance the larger profession of teaching" (Huber \& Hutchings, 2005, p. 1). The scholars who 
engage in this type of research bring their disciplinary background when they conduct scholarship in teaching and learning, which can lead to debate about how best to conduct SoTL research (Huber, 2010). In other words, SoTL scholars may choose to conduct their research according to the conventions of their discipline (e.g. as a biologists or sociologist) or within the conventions of SoTL (e.g. as an educator in Biology).

Despite over two decades of SoTL and increasing requirements for faculty to "engage in scholarship" (University of British Columbia collective agreement), the scholarliness of SoTL remains contested. This may lead to uncertainty, especially for faculty originating from a positivist tradition. SoTL may be equated with pedagogic research, and that is certainly part of its definition, but SoTL is wider than just that. It is the amalgamation of pedagogic research, and understanding of education theory and literature, reflection on one's practice as a teacher in higher education, and a learning-centred conception of education. Through literature informed, rigorous methodological inquiry, and peer disseminated findings, SoTL provides a practical and complementary undergirding for research into teaching and learning (Hubball et al., 2015).

Engaging with SoTL remains difficult, as newly recruited faculty may be unaware of the existence of SoTL. It is unusual for postgraduate students to engage with SoTL even if they have substantial teaching assistant responsibilities, as emphasis is placed on disciplinary knowledge. However, this may be changing with the introduction of programmes which support postgraduate teaching assistants. In general, the first contact with SoTL is usually during probationary activities in a first academic role. In contrast, some SoTL programmes target mid-career faculty who are charged with leading curricular and/or pedagogical changes in departments, faculties, and institutions. While new faculty are expected to be experts in their discipline, in contrast, it is not expected that they are pedagogic experts, and this learning only starts after being hired, with 
the introduction to pedagogy commonly taking place during attendance at a PGCert course (Smith, 2011). The seriousness institutions place on pedagogic skills varies. In general, higher value is placed on the signature pedagogy within the discipline (Shulman, 2005). This situation perpetuates each new generation of faculty underprepared as to the pedagogic responsibilities of their new role. Learning about pedagogy in higher education, therefore, presents a series of challenges for faculty. Our research highlights that both new and experienced faculty struggle with the challenges of SoTL research.

Threshold Concepts. A useful lens for exploring the challenges of SoTL faced by faculty is that of threshold concepts (Meyer \& Land, 2003; 2005). Threshold concepts "can be considered as akin to a portal, opening up a new and previously inaccessible way of thinking about something" (Meyer \& Land, 2003, p.1). More than just key concepts or pieces of knowledge, threshold concepts represent an entirely new way of understanding a subject, one that can be troublesome but ultimately transformative for the learner. Emerging out of a largescale collaborative project involving universities across the United Kingdom, threshold concepts have recently generated a great deal of interest internationally, including being labeled as an innovation with the potential to provoke a major shift in higher education (Sharples et al., 2014). Originally focused on improving teaching and learning within disciplines, recent studies illustrate that threshold concepts are also useful for initiating cross- and inter-disciplinary discourses (Carmichael, 2010); acting as a starting place for curriculum making (Carmichael, 2012). Threshold concepts resonates with many educators as a heuristic tool that offers previously unarticulated insights into learning. Understanding core concepts must be correctly constructed for learning to progress. However, threshold concepts lead to a qualitatively different understanding of the subject matter. In this way, they are central to achieving mastery of the 
ways of thinking and practicing in a field and transform learners into practitioners (Meyer \& Land, 2003; 2005; 2007). As such, the adoption of threshold concepts for curricular and pedagogical investigations could prove significantly beneficial for institutions, departments, and individual educators; such as programs for those new to SoTL.

Related to the threshold concepts framework is the notion of liminality. The process of learning might cause learners to experience liminality (Meyer \& Land, 2006); a 'liquid' space of oscillation. In the liminal space, learners are simultaneously transforming and being transformed (Meyer \& Land, 2005). Liminality requires moving through a necessary and important difficult, yet transformational landscape

Much of the threshold concepts research is based within specific disciplines or courses, and is centred on the undergraduate, for example (Smith, 2012) or postgraduate experience (Keefer, 2015), or an exploration of educational developers (Timmermans, 2013). Focusing on the 'stuck places' in SoTL, one research projects considers the experience of faculty members previously and currently enrolled in a SoTL program, while the other examines the ad hoc development of life scientists' understanding of SoTL. The studies that we pursued uncovered the nature of threshold concepts in SoTL in two contrasting contexts: the Canadian study explored the factors that supported or hindered university level educational leaders as they develop expertise SoTL, while the UK Study focused on the barriers to engaging with SoTL for teaching-focused Life Sciences faculty.

\section{Research Approaches}

Our studies adopted different yet aligned research approaches with different groups of educational leaders. In taking an interpretive phenomenological (van Manen, 1997) (by Webb) and Activity Theory (Engeström, 1987, 2000) (by Tierney) approach, both studies revealed 
similar ontological and epistemological transformations within both populations. Aligned with these transformations was experience of liminality, in terms of knowledge, expertise and academic identity. Despite different institutional contexts and individual disciplinary backgrounds of the participants, both studies outlined the essential need for institutional support for educational leadership in higher education.

\section{Study 1: SoTL and UK teaching-focused Life Science faculty}

This study concentrated on the social world inhabited by teaching-focused faculty, utilising Activity Theory to explore the component parts of that social world. As such, it was a hermeneutic study, relying on the interpretation of survey and interview data to build a picture of the activities and challenges faced by teaching-focused faculty. Twenty-one volunteer individuals met the selection criteria of a purposive sample and were interviewed from a range of UK universities and academic roles within Life Sciences departments.

Activity Theory proved to be a fruitful methodological framework for investigating the place of SoTL in relation to the role of the teaching-focused faculty in Life Sciences. Using the third-generation activity theory framework (Engeström, 2000), the complexity of the relationship between SoTL and the disciplinary faculty who practice it can be extensively explored. By examination of each of the dimensions of the activity system; tools, community, rules and division of labour, we come to a greater understanding of the place of SoTL within the teachingfocused faculty activity system.

Findings. SoTL can be identified as a tool that teaching-focused faculty use to develop their teaching practice. This increases the repertoire of faculty, moving them from practising traditional, didactic lectures, to a broad variety of teaching and learning methods. The variety of teaching methods employed by Life Science faculty cannot solely be attributed to SoTL, as 
laboratory practicals, tutorials, seminars and fieldwork have always featured as part of a Life Sciences course. However, SoTL can be attributed to the study of how best to organise and present these learning opportunities. It is perhaps the variety of teaching opportunities available to Life Sciences faculty which makes them ideally suited to engaging with SoTL. Teachingfocused faculty, in particular, have embraced SoTL as a means to reclaim their academic identity, forging a new academic identity from a precarious status brought about by no longer being research-active in a culture which values high stakes research (Becher \& Trowler, 2001).

That SoTL is a tool for teaching-focused faculty also explains how it is able to act as a focus for a community of practice (Wenger, 1998). Teaching-focused faculty may find themselves isolated in a research-intensive university department. Their natural inclination is to gravitate towards other, similarly interested individuals. This may be through completion of a postgraduate certificate in higher education, or via external agencies, such as learned societies. Conversely, communities of practice within departments are more loosely held together than those organised externally, perhaps because of the prevalence of the disciplinary research culture.

Considering institutional rules and division of labour together is useful when thinking of SoTL. Rules on promotion and progression of faculty include a requirement for research and/or scholarship. For teaching-focused faculty, this is generally translated to mean SoTL in the form of pedagogic research (PedR). However, institutional rules generally favour (in Life Sciences in particular) disciplinary research, rewarding acquisition of large research grants and advances in scientific research. On those terms, SoTL cannot compete, as it is underfunded, and generally done on a small scale. The discrepancy is further compounded by the division of labour, where teaching-focused faculty take on the bulk of teaching and associated administrative tasks within 
a department, so that time becomes an issue for engagement with SoTL. This impacts in two ways; SoTL as PedR is generally small scale, and also may result in practice narratives, rather than scholarly, evidence-based studies, grounded in theory. This is where threshold concepts (Meyer \& Land, 2003; 2005) becomes a useful lens in understanding how Life Science teachingfocused faculty begin to understand and negotiate an unfamiliar paradigm. Despite being disciplinary specialists, the teaching-focused faculty were building up a new area of expertise and were revisiting feelings of liminality and uncertainty.

\section{Study 2: SoTL and educational leadership at a Canadian research-intensive university}

The University of British Columbia Scholarship of Educational Leadership Program

(UBC SoEL Program) is a learning-centred programme for institution-level/Faculty-level educational leaders. Begun in 1998, this programme strategically evolved from an initial focus on the scholarship of teaching and learning, to its current focus on SoTL Leadership. Nominated educational leaders engage in SoTL Leadership initiatives to strategically impact the quality of teaching, learning and/or curriculum practices within Faculty-specific or Institutional-level contexts (Hubball et al., 2015).

Given that the study aimed to understand the nature and substance of threshold concepts in SoTL, an interpretive phenomenological inquiry was determined to be the most appropriate approach. This allowed an in-depth understanding of the lived experience of educational leaders as SoTL scholars and the personal meaning making that they attribute to their experience (van Manen, 1997). The data collected consisted of participant observation of UBC SoTL Leadership Program classroom sessions, one-on-one semi-structured interviews, portfolio documents, and entries in the researcher's journal. 
van Manen (1997) outlined six steps that informed the research procedure of this study.

These steps are: 1) turning to a phenomenon of interest; 2) investigating experience as lived rather than conceptualized; 3) reflecting on the essential themes; 4) describing the phenomenon through writing and re-writing; 5) maintaining a focus on the phenomenon; and 6) balancing the research by considering the parts and the whole. While the research did not follow the steps in a linear process, each was important in the collection and analysis of the corpus of data.

Findings. Over the sixteen years of the UBC SoEL Program, some participants have become more active in SoTL (institutionally and nationally), and others have confined the effects of the programme to their classrooms. Some participants suggested that they came to the UBC SoEL Program with an interest in change (both personal and professional) and consciously put themselves in intellectually and ontologically challenging positions. But, almost all recognized that their experience changed their whole approach to learning. Developing curiosity about the classroom was identified as an introductory way into authentic educational questions. While the educational leaders who became novice SoTL scholars cultivated the identity of an educator, they often adopted mimicry to facilitate early SoTL inquiry. Interestingly, this mimicry happens at all levels, for novice and experienced faculty. While their position as a novice was scary, many cited the increase in confidence as an important aspect of their continued SoTL work.

The findings of this study suggest that it was important to draw upon a holistic view of scholarship, especially when it came to integrating the unique practices of an interdisciplinary field like SoTL. Participants recognized that the ability to transcend disciplinary boundaries was instrumental in navigating their uncertainty. A research framework and research paradigm, previously used to identify threshold concepts in doctoral education (Kiley \& Wisker, 2009), was useful in identifying developing SoTL practice. Issues such as the language and discourse of 
SoTL and recognition of teaching as public, researchable act were highlighted as foundations for developing SoTL scholarship. While each novice SoTL scholar's experience is unique, this study sheds light on effective ways to support educational leaders and teaching-focused faculty, connecting these 'lonely planets,' and thus foster communities of practice around the scholarship of teaching and learning.

\section{Results \& Discussion}

Despite different research sites, the populations and methodologies were aligned and yielded similar results.

Scholarship as a threshold concept. Whilst reading the scholarship of others is troublesome, producing one's own scholarship is also a challenge. Research methodology, methods, data collection and analysis, and even the acknowledgement of what is recognized as data, may all be thought of as thresholds in SoTL. For many faculty, the thought of using thoughts, words, and opinions as data is foreign. While faculty are able to acknowledge the methodologies, and even carry them out, there is often still a sense of unease that the research being conducted is not rigorous compared to that of the discipline. While these feelings of unease are related to the dissimilarity between disciplinary and pedagogic methodologies, any faculty may experience liminality when faced with unfamiliar theory.

This finding supports the work of Kanuka (2011) and Svinicki (2012). It is often taken for granted that participants are excellent researchers, however they are not familiar or comfortable with educational research. As instructional teams, we often assumed that the participants, all successful scholars in their own fields, would be as skilful in their research in SoTL. But this assumption misses the key and fundamental issue that they are engaging in scholarship in a new field, which may or may not connect with the field/discipline of their 
training. Educational leaders and teaching-focused faculty, as SoTL scholars, need to be guided through the language and culture of a new field.

Being a novice. Despite being an expert in their discipline, they may still be novices with regards to SoTL. The distance they have to travel may also be influenced by their preceding disciplinary knowledge. Kelly, Nesbit, and Oliver (2012) make a compelling case for the transition from Science, Technology, Engineering, and Mathematics (STEM) to SoTL, citing a timespan of up to ten years to make the transition. Therefore, although faculty may be experts in their disciplinary area, they are required to restart the process when they move to another area. The existence of thresholds is apparent, particularly with STEM faculty because of the contrast between paradigms.

Forming a new identity. Previous threshold concepts studies have discussed identity transformation (Meyer, 2012) and ontological shifts (Trafford \& Lesham, 2009) as key aspects of threshold concepts mastery. Both SoTL leadership candidates and Life Science teachingfocused faculty showed similar epistemological and ontological thresholds in relation to their perceptions of SoTL. Epistemologically, SoTL presents a number of challenges to faculty. Working within an unfamiliar paradigm is the most obvious of the thresholds; however, this can be broken down further to reveal the complexity of the challenge, which is further complicated by the relationship between the individual's own disciplinary norms and those of SoTL. Firstly, the ability to engage effectively with education theory can be identified as a threshold concept, particularly for those individuals coming from a positivist standpoint. Language can be impenetrable, knowledge may be alien, even the reasons for the use of theory may be foreign. Related to education theory is engagement with pedagogic literature. While the past twenty years have witnessed an explosion in SoTL papers, there tends to be a separation within disciplines, so 
that practitioners may confine themselves to SoTL papers written about their own discipline, by fellow practitioners, and find mainstream SoTL written by education researchers off-putting, and troublesome.

Throughout our research, evidence of epistemological and ontological shifts was subtle. The epistemological and ontological shifts central to threshold concept learning (Cousin, 2006; Irving \& Carmichael, 2009; Meyer \& Land, 2005; Walker, 2013) were evident in the discourse and questions, but participants do not appear to recognize any changes until they reflected on the experience after the programme. Similar to the findings of Kandlbinder and Peseta (2009), learning in a faculty development programme transcends the length of the programme. One of the participants (Webb, 2015) noted that her understanding of SoTL before and after her experience was different, but she was unable to pin it down to particular events, topics, or resources. A number of participants felt that the a-ha moments tended to be at the micro level. It was the holistic experience of incremental change that helped them integrate an irreversible foundation for SoTL research. The participants' emphasis on the importance of ongoing engagement with SoTL suggests that the engagement of the programme alumni is significant in order to support the building and maintenance of SoTL capacity at an institution.

Importance of reflection. Reflective practice (Schon, 1984; Kreber, 2007) has been much explored in the literature. Novice SoTL scholars need, and request, time to discuss their developing conceptions of SoTL, the feasibility of research questions, the adopted methodology as well as methods, and the ethical considerations of pedagogical or curriculum research. Time to interact with other participants and programme graduates, especially as many novice SoTL scholars feel isolated and foresee little support within their home departments or faculties, can help to increase the rigor of the SoTL project and the confidence of the researcher. This type of 
programme would require the allotment of significant classroom time to go into depth on some of the pressing issues. Unfortunately many institutions lack the internal SoTL expertise and available time to effectively develop supportive mentoring programmes.

Underpinning the results of these studies is the reality that educational leaders and teaching-focused faculty are situated within a complex network of personal, professional, and financial tensions. The institutional culture of a department, faculty, or university operates within and against this complex network. There are two levels of institutional culture: the larger university level which supports SoTL Leadership initiatives and the pervasive faculty or department level which controls the first steps toward promotion, tenure, and merit. The local level of institutional culture is key in determining what research is done and how it proceeds. While this research corroborates what Bunnell and Bernstein (2012) have suggested as threshold concepts for faculty members who engage in scholarly teaching, it also adds specific examples that document the perceived and real institutional challenges. There are so many barriers to change (Hubball \& Pearson, 2010; Webb et al., 2013) including entrenched systems of credit hours, scheduling, methods of teaching and assessment, departmental or disciplinary silos, administration systems, and reward systems that value research over pedagogical or curricular leadership.

\section{Recommendations}

Higher education institutions need to foster institutional cultures that predispose, enable, and reinforce educational leaders and teaching-focused faculty to actively engage in SoTL. The engagement of these individuals could be achieved through the development of an institutional culture that values scholarship in teaching and learning as well as disciplinary scholarship. Underpinning these recommendations is the need for a department, school, faculty, and 
university that values the scholarship of teaching and learning equally to disciplinary research. The fact that educational scholarship may be seen as an addition to participants' professional responsibilities could provide a major barrier. SoTL scholarship cannot be done as an 'off the side of the desk' process; those who try to do this struggle. It needs to be seen as part of professional culture in higher education and to inform all pedagogical and curricular changes. Providing SoTL scholars with the time, through differentiated workloads and strategic SoTLbased programmes, and resources for their inquiry serves to support superior quality work in the field. While these arguments have been made in the past, we offer four evidence based recommendations: sustained and ongoing support for SoTL; reward and recognition; not pitting disciplinary research and SoTL against each other; and acknowledging the complexity of social science research.

Sustained support for SoTL. Kelly, Nesbitt, and Oliver (2012) tell us that it takes 10 years to become part of the SoTL community. So a program, such as a PGCert, is a good place to start, but what happens after the program? A combination of formal and informal networks (e.g., communities of practice, book clubs, mentors), differentiated workloads, and possible advanced qualifications all serve to keep novice SoTL scholars continuing in the field.

Reward and recognition. With the requirement of SoTL in the job description of teaching-focused faculty, there has to be recognition and reward, to incentivize academics, much the way that tenure and promotion do.

Disciplinary research vs. SoTL. All too often a false dichotomy is created by pitting disciplinary research against scholarship in teaching and learning; with disciplinary research seen a more legitimate form of scholarship. First, both fields have conventions for ensuring credibility 
(Billot, Rowland, Carnell, Amundsen, \& Evans, 2017) and second, disciplinary research and teaching can benefit from the inclusion of SoTL research.

Complexity of social science research. As scholars who are learning ton conduct research in a new field, novice SoTL scholars have to acknowledge the complexity of social science research (Regehr, 2010). Often this can take a long time as it takes a while for researchers to come to grips with the complexity of what they are doing.

At a local level, be it faculty or department, faculty development programmes in the scholarship of teaching and learning need to support and sustain communities of practice, develop increased capacity for educational research, and support institutional cultures that stretch across disciplines. Developing a cohesive community of practice within each cohort and across the institution engages interdisciplinary support for novice SoTL scholarship. Rather than seeing the instructional team as the only resources, cohort members need time to discuss their developing conceptions of SoTL, the feasibility of research questions, the adopted methodology as well as methods, and the ethical considerations of pedagogical or curriculum research. Having institutional policies fostering SoTL is only useful if they are also supported at the local level.

As a field, SoTL scholars must continue to advocate for an increased connection between SoTL scholarship and practice, focus on articulating rigorous, literature informed methodologies as well as methods, and continue to theorize with the scholarship of teaching and learning. As stakeholders within our field, we are responsible for demanding high quality research and scholarship that continues to support exceptional programs and teaching and learning practices in higher education. In order to do this, we must address the institutional challenges while supporting educational leaders and teaching-focused academics as they navigate SoTL. This 
support needs to come in many forms including recognition, strategic mentoring, incentives, resources, and most importantly, time.

\section{Acknowledgements}

The authors wish to thank the participants at ProPEL 2017 who offered valuable feedback for this paper.

\section{Declaration of interest}

The authors report no conflicts of interest. The authors alone are responsible for the content and writing of this article. 
INSTITUTIONAL SUPPORT FOR SOTL EDUCATIONAL LEADERSHIP

\section{References}

Becher, T., \& Trowler, P. (2001). Academic tribes and territories: Intellectual enquiry and the cultures of disciplines (2nd ed.). Open University Press.

Billot, J., Rowland, S., Carnell, B., Amundsen, C, \& Evans, T. (2017). How experienced SoTL researchers develop credibility of their work. Teaching \& Learning Inquiry, 5(1). Available at http://dx.doi.org/10.20343/teachlearninqu.5.1.8

Bunnell, S.L., \& Bernstein, D.J. (2012). Overcoming some threshold concepts in scholarly teaching. Journal of Faculty Development, 23(3), 14-18.

Carmichael, P. (2010). Threshold concepts, disciplinary differences and cross-disciplinary discourse. Learning and Teaching in Higher Education: Gulf Perspectives, 7(2), 53-71.

Carmichael, P. (2012). From this curriculum to that which is to come. NAIRTL Conference 2012, Trinity College Dublin, June 28-29, 2012. Retrieved on July 10, 2013 from www.nairtl.ie/index.php?pageID=634.

Cousin, G. (2006). An introduction to threshold concepts. Planet, 17, 4-5.

Engeström, Y. (1987). Learning by expanding: An activity-theoretical approach to developmental research. Helsinki: Orienta-Konsultit.

Engeström, Y. (2000). Activity theory as a framework for analysing and redesigning work. Ergonomics, 43(7), 960-974.

Hubball, H.T., \& Clarke, A. (2010). Diverse methodological approaches and considerations for SoTL in higher education. The Canadian Journal for the Scholarship of Teaching and Learning 1(1). Available at http://ir.lib.uwo.ca/cjsotl_rcacea/vol1/iss1/

Hubball, H.T., Clarke, A., Webb, A.S., \& Johnson, B. (2015). Developing institutional leadership for the scholarship of teaching and learning: Lessons learned with senior 
INSTITUTIONAL SUPPORT FOR SOTL EDUCATIONAL LEADERSHIP

educational leaders in multi- national and multidisciplinary research university settings. International Journal for University Teaching and Faculty Development, 4(4), 237.

Hubball, H., \& Pearson, M. (2010). Grappling with the complexity of undergraduate degree program reform: Critical barriers and emergent strategies. Transformative Dialogues, 3(3), 3-3.

Huber, M.T. (2010). Editorial: CASTL has concluded. Long live the scholarship of teaching and learning. Arts and Humanities in Higher Education, 9(1), 5-8.

Huber, M. T., \& Hutchings, P. (2005). Surveying the scholarship of teaching and learning. The advancement of learning: Building the teaching commons. 1-16.

Kanuka, H. (2011). Keeping the scholarship in the scholarship of teaching and learning. International Journal for the Scholarship of Teaching and Learning, 5(1). Available at http://www.georgiasouthern.ed/ijsotl/v5n1/invited_essays/Kanuka/index.html

Keefer, J. M. (2015). Experiencing doctoral liminality as a conceptual threshold and how supervisors can use it. Innovations in Education and Teaching International, 52(1), 1728. http://doi.org/10.1080/14703297.2014.981839

Kelly, N., Nesbit, S., \& Oliver, C. (2012). A Difficult Journey: Transitioning from STEM to SoTL. International Journal for the Scholarship of Teaching and Learning, 6(1), Article 18.

Kiley, M., \& Wisker, G. (2009). Threshold concepts in research education and evidence of threshold crossing. Higher Education Research and Development, 28(4), 431-441. doi: $10.1080 / 07294360903067930$ 
INSTITUTIONAL SUPPORT FOR SOTL EDUCATIONAL LEADERSHIP

Kreber, C. (2007). What's it really all about?: The scholarship of teaching and learning as an authentic practice. International Journal for the Scholarship of Teaching and Learning, 1(1). Available at http://www.georgiasouthern.edu/ijsotl/2007_v1n1.htm

Meyer, J.H.F. (2012). Variation in student learning as a threshold concept. Journal of Faculty Development, 26(3), 8-13.

Meyer, J. H. F., \& Land, R. (2003). Threshold concepts and troublesome knowledge: Linkages to ways of thinking and practising within the disciplines. In Improving student learning: Improving student learning theory and practice - Ten Years On. (Rust, C. (Ed)). Oxford: Oxford Centre for Staff and Learning Development.

Meyer, J. H. F., \& Land, R. (2005). Threshold concepts and troublesome knowledge (2): Epistemological considerations and a conceptual framework for teaching and learning. Higher Education, 49, 373-388.

Regehr, G. (2010). It's NOT rocket science: Rethinking our metaphors for research in health professions education. Medical Education, 44(1), 31-39. doi: 10.1111/j.13652923.2009.03418.x

Schon, D. A. (1984). The reflective practitioner: How professionals think in action (Vol. 5126). Basic books.

Sharples, M., Adams, A., Ferguson, R, Gaved, M. McAndrew, P., Weller, M., \& Whitelock, D. (2014). Innovating Pedagogy 2014: Open University Innovation Report 3. Milton Keynes: The Open University. Available at http://www.open.ac.uk/blogs/innovating/?p=3

Shulman, L. S. (2005). Signature pedagogies in the professions. Daedalus, 134(3), 52-59. 
INSTITUTIONAL SUPPORT FOR SOTL EDUCATIONAL LEADERSHIP

Smith, J. (2011). Resonance, Dissonance, Rejection: Experiences of Probationary Lecturers in UK Higher Education (PhD dissertation). University of Strathclyde, Glasgow, U.K.

Smith, K. (2012). An investigation of student learning using threshold concepts in a first year cell biology course (Masters thesis). University of British Columbia, Vancouver, B.C., Canada. Available at https://circleprod.library.ubc.ca/bitstream/handle/2429/41938/ubc_2012_spring_smith_karen.pdf?seq uence $=1$.

Svinicki, M.D. (2012). “Who is entitled to do SoTL?” International Journal for the Scholarship of Teaching and Learning, 6(2). Available at http://www.georgiasouthern.edu/ijsotl/v6n2/invited_essays/Svinicki/index.htm

Tierney, A.M. (2016). "More than just A Teaching Fellow": The impact of REF and implications of TEF on Life Science Teaching-Focused Academics in UK HEIs (Doctoral thesis). University of Durham, Durham, U.K.

Timmermans, J. A. (2013). Identifying threshold concepts in the careers of educational developers. International Journal for Academic Development, 19(4), 305-317. https://doi.org/10.1080/1360144X.2014.895731

Trafford, V., \& Leshem, S. (2009). Doctorateness as a threshold concept. Innovations in Education and Teaching International, 46(3), 305-316. doi: $10.1080 / 14703290903069027$

van Manen, M. (1997). Researching lived experience: Human science for an action sensitive pedagogy (2nd ed.). Albany, NY: State University of New York Press.

Walker, G. (2013). A cognitive approach to threshold concepts. Higher Education, 65(2), 247263. doi: 10.1007/s 10734-012-9541-4 
Webb, A.S. (2015). Threshold Concepts in the Scholarship of Teaching and Learning: A phenomenological study of educational leaders in a Canadian Research Intensive University Context (PhD dissertation). University of British Columbia, Vancouver, B.C., Canada.

Webb, A.S., Wong, T., \& Hubball, H.T. (2013). Professional development for adjunct teaching faculty in a research-intensive university: Engagement in scholarly approaches to teaching and learning. International Journal for Teaching and Learning in Higher Education, 25(2), 231-238.

Wenger, E. (1998). Communities of Practice: Learning, meaning, and identity. Cambridge University Press. 